\title{
Intralesional Steroid Injection to Prevent Stricture after Near-Circumferential Endosopic Submucosal Dissection for Superficial Esophageal Cancer
}

\author{
Wook Jin Lee, Hwoon-Yong Jung, Do Hoon Kim, Jeong Hoon Lee, Kee Don Choi, Ho June Song, \\ Gin Hyug Lee and Jin-Ho Kim \\ Department of Gastroenterology, Asan Medical Center, University of Ulsan College of Medicine, Seoul, Korea
}

\begin{abstract}
Stricture frequently occurs after endoscopic submucosal dissection (ESD) for superficial esophageal carcinoma with near- or whole-circumferential mucosal defects, and post-ESD stricture is difficult to treat and usually requires multiple sessions of endoscopic balloon dilatation. Intralesional steroid injection has previously been used to prevent stricture; however, there have been few experiences with this method after near- or whole-circumferential ESD. We present a case of a single session of intralesional steroid injection performed immediately after near-circumferential ESD to prevent post-ESD stricture. After a follow-up period of 6 months, the patient showed good outcome without dysphagia.
\end{abstract}

Key Words: Injections, intralesional; Esophageal stenosis; Endoscopic submucosal dissection; Esophageal neoplasms

\section{INTRODUCTION}

Endoscopic submucosal dissection (ESD) has been performed widely and safely as an established treatment for superficial esophageal neoplasms. ${ }^{1}$ To date, the indication for ESD has been gradually extended to larger lesions. However, as large superficial esophageal neoplasms became candidates for ESD, a substantial number of post-ESD strictures have been reported. ${ }^{2}$ In particular, esophageal stricture mostly occurs after near-circumferential or whole-circumferential ESD at a rate of $88 \%$ to $100 \%{ }^{3}$ Post-ESD stricture decreases the patients' quality of life and usually requires multiple sessions of risky endoscopic balloon dilatation (EBD). ${ }^{4}$

Recently, the efficacy of prophylactic oral prednisolone in preventing post-ESD stricture was reported. ${ }^{5}$ According to the report, oral prednisolone may be effective in reducing the

Received: October 10, 2012 Revised: November 18, 2012

Accepted: November 22, 2012

Correspondence: Hwoon-Yong Jung

Department of Gastroenterology, Asan Medical Center, University of Ulsan College of Medicine, 88 Olympic-ro 43-gil, Songpa-gu, Seoul 138-736, Korea Tel: +82-2-3010-3180, Fax: +82-2-476-0824, E-mail: hyjung@amc.seoul.kr

(c) This is an Open Access article distributed under the terms of the Creative Commons Attribution Non-Commercial License (http://creativecommons.org/ licenses/by-nc/3.0) which permits unrestricted non-commercial use, distribution, and reproduction in any medium, provided the original work is properly cited. need for EBD. However, the cumulative dose of prednisolone was high and associated with serious adverse events. Intralesional steroid injection is a novel method to prevent post-ESD stricture. A previous study reported that intralesional injection of triamcinolone reduced the incidence of stricture and the number of required EBD sessions. ${ }^{6}$ However, there is little experience in intralesional steroid injection for near- or wholecircumferential ESD ulcerations. Furthermore, there is no established method of injection to date.

We report a patient with superficial esophageal squamous cell carcinoma who underwent complete near-circumferential ESD and then received a single session of intralesional steroid injection immediately after ESD. Dysphagia and the need for EBD have not developed after a follow-up period of 6 months.

\section{CASE REPORT}

A 72-year-old man visited our hospital for the treatment of esophageal cancer. He had undergone a low anterior resection for colorectal cancer 1 year previously. Oral capecitabine was administered after surgery as an adjuvant treatment. There were no significant abnormal findings in the physical examination. All the laboratory findings were within normal 

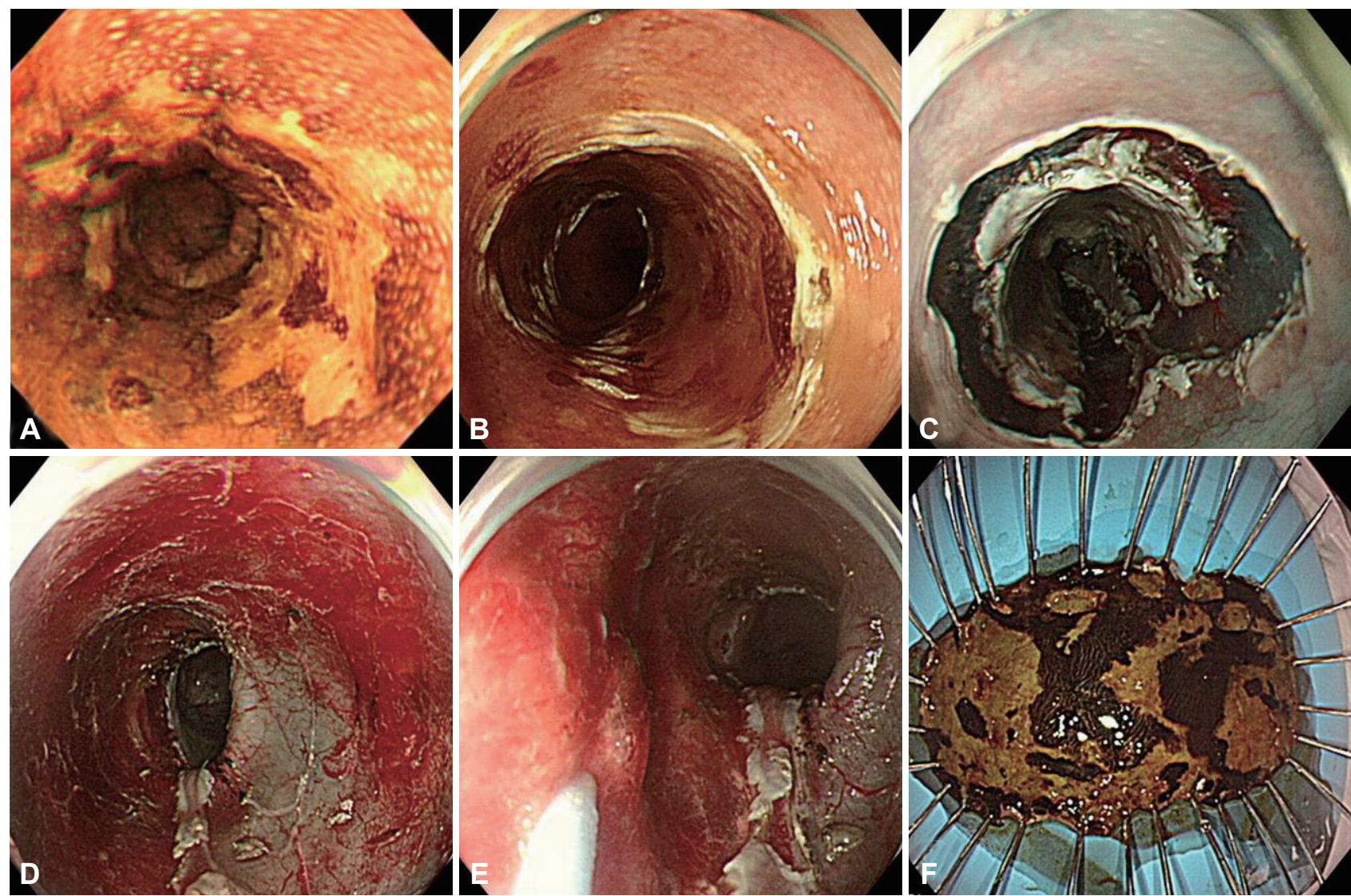

Fig. 1. (A) Upper endoscopy with lugol solution reveals an unstained area in the lower esophagus. The superficial esophageal carcinoma involves almost the whole circumference of the esophageal lumen. (B) Circumferential markings are made by a hook knife just outside the lesion. (C) Precutting is made with a hook knife. (D) Near-circumferential endoscopic submucosal dissection is performed. (E) Triamcinolone is injected into the deep submucosa and the superficial proper muscle layer of the ulcer base. $(F)$ The tumor is removed en bloc.

limits. Computed tomography and positron emission tomography revealed no distant metastasis. An initial upper endoscopy showed a lugol-voiding lesion involving more than threequarters of the circumference of the lower esophagus, extending 39 to $43 \mathrm{~cm}$ from the incisors (Fig. 1A). Endoscopic ultrasound revealed no evidence of submucosal invasion or regional lymph node metastasis. Histopathological findings from another hospital revealed high-grade squamous cell dysplasia, but squamous cell carcinoma could not be excluded. We decided to perform ESD. Because the lesion was near circumferential, a high probability of post-ESD stricture was expected. In this case, we needed to obtain clearer views and to control the scope in detail throughout the procedure; therefore, this patient underwent ESD with tracheal intubation and general anesthesia in an operating room.

The ESD procedure was performed using a single-channel upper endoscope (GIF-H260Z; Olympus, Tokyo, Japan) with a transparent cap. Circumferential markings were made using a hook knife (KD-620LR; Olympus) just outside the lesion, on soft coagulation mode of a high-frequency generator for electrosurgery with an automatically controlled system for cutting and coagulation (ERBE, Tübingen, Germany). A total amount of $80 \mathrm{~mL}$ normal saline solution mixed with epinephrine was injected into the submucosal layer to lift the mucosa including the tumor. After the lesion was lifted, mucosal incision and dissection was made with a hook knife and an IT knife (KD-611L; Olympus) (Fig. 1B, C). The en bloc resection was completed without complications (Fig. 1D). Bleeding in the post-ESD ulcer was coagulated with hemostatic forceps. The total procedure time was approximately 55 minutes. Just after dissection and hemostasis, a single-session endoscopic triamcinolone injection was administered (Fig. 1E). Triamcinolone acetonide (Triam, $40 \mathrm{mg} / \mathrm{mL}$; Shinpoong Co., Seoul, Korea) was diluted with saline to make a $20 \mathrm{mg} / \mathrm{mL}$ solution. A total of $80 \mathrm{mg}(4 \mathrm{~mL})$ triamcinolone was injected into the deep submucosa and the superficial proper muscle layer of the ulcer base at eight sites, with a $0.5 \mathrm{~mL}$ dose at each site. The depth of needling was as shallow as producing a small amount of spillage into the esophageal lumen side during injection to avoid possible abscess formation. The resected area was $54 \times 27 \mathrm{~mm}$ in size. Three neoplastic lesions $(38 \times 17$, $11 \times 7$, and $7 \times 3 \mathrm{~mm}$ ) were found in the specimen (Fig. 1F). The histopathologic diagnosis was well-differentiated intramucosal invasive carcinoma confined to the lamina propria 


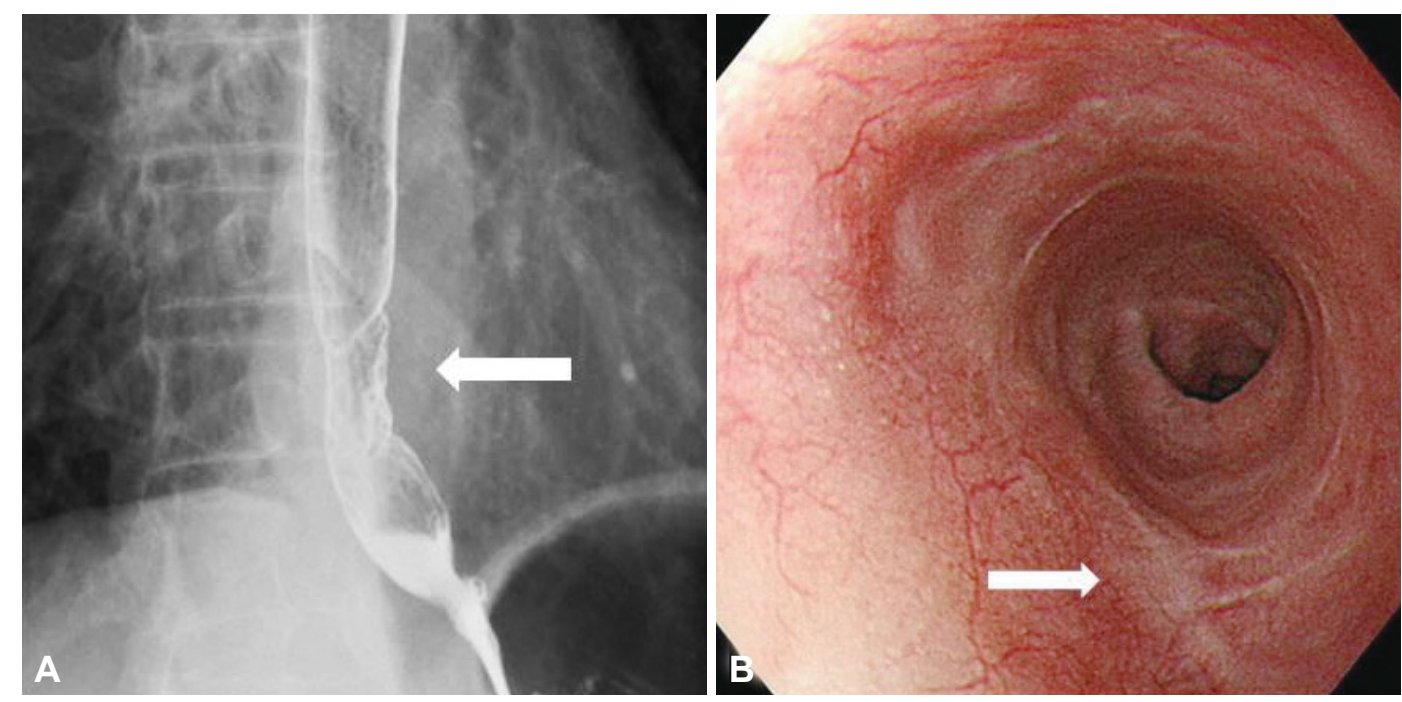

Fig. 2. (A) Follow-up esophagography 4 weeks later reveals minimal segmental luminal narrowing (arrow) without passage disturbance. (B) Follow-up endoscopy 4 months later shows only a scar (arrow).

without lymphovascular invasion.

Serial esophagography was performed 2 and 4 weeks later to assess the post-ESD stricture. Mild irregular segmental narrowing was seen in the lower esophagus, but no definite passage disturbance was observed (Fig. 2A). Follow-up upper endoscopy was performed after 4 months, which revealed only a post-ESD scar (Fig. 2B). The scope was passed without resistance. The patient did not complain of dysphagia and showed a good outcome for 6 months after ESD. Moreover, no single session of EBD has been needed.

\section{DISCUSSION}

Post-ESD stricture is a major complication especially in esophageal ESD. In a previous report, multivariate analysis revealed that a circumferential extension of more than threequarters and a histological depth to M2 are reliable independent predictors for post-ESD stricture. ${ }^{3}$ As larger superficial esophageal neoplasms became candidates for ESD, substantial post-ESD strictures have been reported. Indeed, the rate of esophageal strictures after ESD for near-circumferential or whole-circumferential lesions has been reported to be surprisingly as high as $88 \%$ to $100 \% .^{7}$ However, there are no guidelines for the treatment of post-ESD esophageal stricture, and most of the previous studies have been performed retrospectively. Until now, multiple sessions of EBD is the preferred treatment of esophageal stricture regardless of etiology; ${ }^{8}$ however, this can increase the risk of perforation, massive bleeding, and bacteremia. ${ }^{4}$ For this reason, the development of strategies to prevent post-ESD stricture is important. Periodic balloon dilations and temporary stenting were used to prevent post-ESD stricture in some institutes. Fujishiro et al. ${ }^{9}$ reported that repetitive, periodic EBD was effective in controlling and preventing post-ESD stricture. However, Isomoto et al. ${ }^{10}$ reported that a scheduled preventive EBD immediately after ESD was needed in a median of 30 times for circumferential cases. The results were not satisfactory.

Several studies suggested that severe inflammation, fibrosis, and scarring in the exposed submucosa after ESD might play an important role in the formation of stricture. According to that theory, post-ESD stricture might be prevented by controlling such inflammation. ${ }^{11}$ Steroid can inhibit fibrosis by preventing the migration and activation of inflammatory cells and fibroblasts. ${ }^{12} \mathrm{~A}$ few studies reported on the effectiveness of prophylactic oral prednisolone for the prevention of post-ESD stricture. As a result, the rate of stricture was decreased together with the number of needed EBD procedures. ${ }^{5,10}$ However, the cumulative dose of prednisolone administered was approximately 1,000 mg. The potential risks of such a high dose, such as immune suppression, psychiatric disturbance, peptic ulceration, and optical damages, were a cause for concern.

Intralesional steroid injection has also been previously used to prevent stricture after esophageal ESD. Hashimoto et al. ${ }^{6}$ reported that endoscopic intralesional injection of triamcinolone was safe and effective for the prevention of esophageal stricture after ESD for superficial esophageal carcinoma. Triamcinolone was injected into post-ESD ulceration 3, 7, and 10 days after ESD. The total dose of the steroid was much lower than that of oral prednisolone. However, it needed three additional endoscopic procedures, causing inconvenience and additional costs to the patients. Moreover, the enrolled patients had a semicircumferential mucosal defect with a relatively low risk of post-ESD stricture. 
In a controlled prospective study, Hanaoka et al. ${ }^{13}$ showed promising results with a single session of intralesional steroid injection immediately after ESD for preventing post-ESD stricture. Compared with the historical control group, the study group had a significantly lower stricture rate (10\% vs. $66 \%$ ). We injected triamcinolone immediately after ESD in the exposed submucosa of the post-ESD ulceration in the same manner. However, the other authors diluted triamcinolone solution up to $5 \mathrm{mg} / \mathrm{mL}$. Because the total amount of the injected triamcinolone was roughly similar to that in our case $(100 \mathrm{mg}$ vs. $80 \mathrm{mg}$ ), the injected volume and the number of needlings were larger than those in our case $(10 \mathrm{~mL}$ vs. $4 \mathrm{~mL}, 20$ to 40 punctures vs. 8 punctures). Therefore, our method of steroid injection was much simpler than that in any previous study. Furthermore, our patient had a near-circumferential mucosal defect, whereas other studies excluded patients with nearcircumferential defects because of the extremely high risk of esophageal stricture.

Because injected triamcinolone usually remains locally active for 3 to 4 weeks, we did not repeat the injection. ${ }^{14}$ In this case, no adverse events related to triamcinolone injection occurred. However, a previous animal study reported that direct injection of triamcinolone into the exposed esophageal submucosal tissue of four pigs resulted in the complication of esophageal abscess. ${ }^{15}$ In addition, potential risks of perforation, mediastinitis, and pleural effusion may be associated with local injection therapy. To prevent excessively deep mural injection, we performed the triamcinolone injection very carefully while checking for minor spillage from the injection site.

There are no standard guidelines to prevent stricture in a patient with near-circumferential or circumferential mucosal defect after ESD. Many methods to prevent post-ESD stricture, such as repetitive EBD, temporary stent insertion, and oral steroid and intralesional steroid injection, have been used by different institutes individually. Because there are no randomized controlled studies comparing those methods, any method cannot be widely accepted. In this case, we showed that a single session of intralesional steroid injection into a post-ESD ulcer was an effective and convenient method to prevent post-ESD stricture. This method of steroid injection was also simpler and safer than those reported in other previous studies. However, the true benefit and the risks of injection have not been validated yet. A randomized, controlled trial would be needed in the future.

\section{Conflicts of Interest}

The authors have no financial conflicts of interest.

\section{REFERENCES}

1. Oyama T, Tomori A, Hotta K, et al. Endoscopic submucosal dissection of early esophageal cancer. Clin Gastroenterol Hepatol 2005;3(7 Suppl 1):S67-S70.

2. Ono S, Fujishiro M, Niimi K, et al. Long-term outcomes of endoscopic submucosal dissection for superficial esophageal squamous cell neoplasms. Gastrointest Endosc 2009;70:860-866.

3. Ono S, Fujishiro M, Niimi K, et al. Predictors of postoperative stricture after esophageal endoscopic submucosal dissection for superficial squamous cell neoplasms. Endoscopy 2009;41:661-665.

4. Takahashi H, Arimura Y, Okahara S, et al. Risk of perforation during dilation for esophageal strictures after endoscopic resection in patients with early squamous cell carcinoma. Endoscopy 2011;43:184-189.

5. Yamaguchi N, Isomoto H, Nakayama T, et al. Usefulness of oral prednisolone in the treatment of esophageal stricture after endoscopic submucosal dissection for superficial esophageal squamous cell carcinoma. Gastrointest Endosc 2011;73:1115-1121.

6. Hashimoto S, Kobayashi M, Takeuchi M, Sato Y, Narisawa R, Aoyagi Y. The efficacy of endoscopic triamcinolone injection for the prevention of esophageal stricture after endoscopic submucosal dissection. Gastrointest Endosc 2011;74:1389-1393.

7. Katada C, Muto M, Manabe T, Boku N, Ohtsu A, Yoshida S. Esophageal stenosis after endoscopic mucosal resection of superficial esophageal lesions. Gastrointest Endosc 2003;57:165-169.

8. Esophageal dilation. Guidelines for clinical application. Gastrointest Endosc 1991;37:122-124.

9. Fujishiro M, Yahagi N, Kakushima N, Kodashima S, Ichinose M, Omata M. En bloc resection of a large semicircular esophageal cancer by endoscopic submucosal dissection. Surg Laparosc Endosc Percutan Tech 2006;16:237-241.

10. Isomoto H, Yamaguchi N, Nakayama T, et al. Management of esophageal stricture after complete circular endoscopic submucosal dissection for superficial esophageal squamous cell carcinoma. BMC Gastroenterol 2011;11:46.

11. Ezoe Y, Muto M, Horimatsu T, et al. Efficacy of preventive endoscopic balloon dilation for esophageal stricture after endoscopic resection. J Clin Gastroenterol 2011;45:222-227.

12. Miyashita M, Onda M, Okawa K, et al. Endoscopic dexamethasone injection following balloon dilatation of anastomotic stricture after esophagogastrostomy. Am J Surg 1997;174:442-444.

13. Hanaoka N, Ishihara R, Takeuchi $Y$, et al. Intralesional steroid injection to prevent stricture after endoscopic submucosal dissection for esophageal cancer: a controlled prospective study. Endoscopy 2012;44: 1007-1011.

14. Roques C, Téot L. The use of corticosteroids to treat keloids: a review. Int J Low Extrem Wounds 2008;7:137-145.

15. Rajan E, Gostout C, Feitoza A, et al. Widespread endoscopic mucosal resection of the esophagus with strategies for stricture prevention: a preclinical study. Endoscopy 2005;37:1111-1115. 